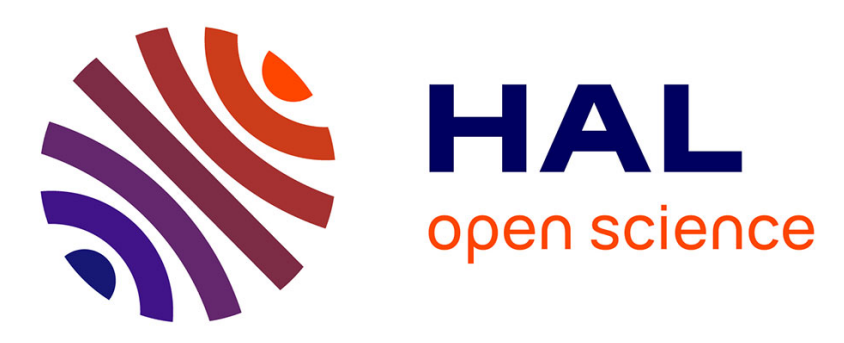

\title{
Hierarchical phase evolution in a lamellar Al0.7CoCrFeNi high entropy alloy involving competing metastable and stable phases
}

K. Srimark, Sriswaroop Dasari, Abhishek B Sharma, P. Wangyao, Bharat Gwalani, T. Rojhirunsakool, Stéphane Gorsse, Rajarshi Banerjee

\section{To cite this version:}

K. Srimark, Sriswaroop Dasari, Abhishek B Sharma, P. Wangyao, Bharat Gwalani, et al.. Hierarchical phase evolution in a lamellar Al0.7CoCrFeNi high entropy alloy involving competing metastable and stable phases. Scripta Materialia, 2021, 204, pp.114137. 10.1016/j.scriptamat.2021.114137 . hal03335223

\section{HAL Id: hal-03335223 \\ https://hal.science/hal-03335223}

Submitted on 13 Sep 2021

HAL is a multi-disciplinary open access archive for the deposit and dissemination of scientific research documents, whether they are published or not. The documents may come from teaching and research institutions in France or abroad, or from public or private research centers.
L'archive ouverte pluridisciplinaire HAL, est destinée au dépôt et à la diffusion de documents scientifiques de niveau recherche, publiés ou non, émanant des établissements d'enseignement et de recherche français ou étrangers, des laboratoires publics ou privés. 


\title{
Hierarchical phase evolution in a lamellar $\mathrm{Al}_{0.7} \mathrm{CoCrFeNi}$ high entropy alloy involving competing metastable and stable phases
}

K. Srimark ${ }^{\mathrm{a}}$, S. Dasari ${ }^{\mathrm{b}}$, A. Sharma ${ }^{\mathrm{b}}$, P. Wangyao ${ }^{\mathrm{c}}$, B. Gwalani $^{\mathrm{b},}$, T. Rojhirunsakool ${ }^{\mathrm{a}}$, S. Gorsse ${ }^{\mathrm{d}}$, and R. Banerjee, ${ }^{\mathrm{b}, *}$

${ }^{a}$ High Temperature Corrosion Research Centre, Department of Materials and Production Technology Engineering, King Mongkut's University of Technology, Bangkok-10800, Thailand.

${ }^{\text {a }}$ Department of Materials Science and Engineering, University of North Texas Denton, TX-76207, USA

${ }^{\mathrm{c}}$ Department of Metallurgical Engineering, Faculty of Engineering, Chulalongkorn University, Bangkok-10330, Thailand

${ }^{\mathrm{d}}$ CNRS, Univ. Bordeaux, Bordeaux INP, ICMCB, UMR 5026, F-33600 Pessac, France

*Corresponding author: raj.banerjee@unt.edu

${ }^{\S}$ Currently at Physical and Computational Sciences Directorate, Pacific Northwest National Laboratory, 902 Battelle Blvd, Richland, WA, 99352, USA

\begin{abstract}
Guided by solution thermodynamic modeling coupled with detailed experimental characterization, the present study establishes that the alternating FCC and BCC lamellar microstructure in the $\mathrm{Al}_{0.7} \mathrm{CoCrFeNi}$ high entropy alloy, is a result of non-equilibrium partitionless solidification from the liquid to single B2 phase, followed by solid-state decomposition. Widmanstätten FCC lamellae form from the allotriomorphic FCC precipitates at the B2 grain boundaries, leading to a lamellar microstructure, divided into two distinct sub-systems. Isothermal annealing further drives these individual sub-systems towards equilibrium via precipitation of ordered intermetallic phases. The transformation in FCC lamellae initiates by the formation of metastable $\mathrm{L}_{2} 2$ precipitates at shorter annealing times, which are eventually replaced by the equilibrium $\mathrm{BCC}$ and $\mathrm{B} 2$ phases, forming composite B2+BCC laths, on long term annealing. These results further exemplify that interesting
\end{abstract}


transformation pathways lead to hierarchical microstructures within HEAs, and the fact that as processed conditions in these alloys are often far-from equilibrium.

Keywords: High entropy alloys; Complex concentrated alloys; Eutectic microstructure; Widmanstatten; Intermetallic precipitates.

High entropy alloys (HEAs) or complex concentrated alloys (CCAs) are a relatively new class of alloys that were developed based on the idea of mixing multiple elements in equiatomic or near equiatomic proportions $[1,2]$. Multiple reports on these alloys show their potential to replace some of the alloys currently being used for structural applications [3-6]. However, much more research is needed to realize their full potential. The ability to control the microstructure and the resulting mechanical properties plays a major role in designing the appropriate HEA/CCA compositions. Understanding the phase transformation pathways in these alloys thus becomes crucial in guiding the microstructural design.

Although $\mathrm{Al}_{\mathrm{x}} \mathrm{CoCrFeNi}$ system has been investigated extensively [7-10], it is an important candidate system for studying the transformation pathways. The $\mathrm{Al}_{\mathrm{x}} \mathrm{CoCrFeNi}$ system also exhibits a eutectic reaction at 14 at. $\% \mathrm{Al}$ and $\sim 1340^{\circ} \mathrm{C}$ where liquid decomposes into $\mathrm{FCC}$ and B2 phases [11]. The compositions $\sim 10$ to 14 at.\% $\mathrm{Al}$ lies in the hypoeutectic regime and $\sim 14$ to $\sim 18$ at.\% $\mathrm{Al}$ lies in the hypereutectic regime. In the hypereutectic compositions, $\mathrm{Al} 0.7 \mathrm{CoCrFeNi}(\sim 15$ at.\% Al) was probably the most studied alloy system [12-20]. The microstructure in the as cast condition of this alloy consists of alternating FCC and BCC based lamellae. Based on this morphology, its microstructure was claimed to be the result of a eutectic reaction from liquid to 
FCC + BCC/B2 $[15,19,20]$. However, a recent study on this microstructure using detailed EBSD analysis revealed that this microstructure is not a result of eutectic reaction but a result of solid state decomposition of parent BCC grains into FCC and BCC [21]. This solid state decomposition leading to a Widmanstatten pattern of FCC lamellae in BCC matrix was accepted by other research groups [22]. Further, this alloy has stable intermetallic phases at lower temperatures which provides an opportunity to investigate the transformation pathways involved in forming the intermetallics in FCC and BCC based phases. Such intermetallic precipitation was also shown to improve the strength of this alloy [20].

In the current study, the microstructure of $\mathrm{Al}_{0.7} \mathrm{CoCrFeNi}$ was investigated in detail using advanced characterization techniques. The results from this study are in agreement with the recent studies on this alloy supporting solid-state decomposition of $\mathrm{BCC}$ based grains into $\mathrm{FCC}$ and $\mathrm{BCC}$ based phases, as opposed to eutectic solidification. However, the current study rationalizes the formation of such microstructure using solution thermodynamic modeling and schematic free energy vs composition curves. Additionally, the microstructural evolution in this alloy upon isothermal annealing at $580^{\circ} \mathrm{C}$ was investigated. Further, the experimental information coupled with thermodynamic modeling has been used to explain the interesting phase transformation pathways observed in this alloy.

Alloy with a nominal chemical composition Alo.7CoCrFeNi (15Al-21.3Co-21.3Cr-21.3Fe-21.3Ni in at.\%) was prepared in conventional vacuum arc melter. The cast ingot was hot rolled to $30 \%$ reduction in thickness at $1100^{\circ} \mathrm{C}$. The hot rolled alloy was subjected to a stress relief annealing treatment at $1100^{\circ} \mathrm{C}$ for $5 \mathrm{~min}$ and thereafter isothermally annealed for the duration of 24 , and 400 
hrs at $580^{\circ} \mathrm{C}$. The nomenclature used for the different conditions is $\operatorname{HRAX}(\mathrm{X}=0,24,400)$. Here, HRA0 corresponds to the high temperature annealed condition $\left(1100^{\circ} \mathrm{C}\right.$ for $\left.5 \mathrm{~min}\right)$. All specimens were encapsulated in quartz tubes backfilled with argon for heat treatments at $1100^{\circ} \mathrm{C}$ and $580^{\circ} \mathrm{C}$ and water quenched.

Microstructural characterization was done using scanning electron microscopy or SEM (FEI NovaNanoSEM 230 ${ }^{\mathrm{TM}}$ ), fixed with energy dispersive spectroscopy (EDS), and electron backscattered diffraction (EBSD) detectors. EBSD data was analyzed in TSL OIM ${ }^{\mathrm{TM}}$ software. The transmission electron microscope or TEM (FEI Tecnai G2 TF20 ${ }^{\mathrm{TM}}$ operating at $200 \mathrm{kV}$ and JEOL JEM-3000F HRTEM operating at $300 \mathrm{kV}$ ) was used to obtain crystallographic information from the phases present in the material. Atom probe tomography (APT) was performed using Cameca LEAP 5000XS 3D Atom Probe Microscope operating at a temperature of $30 \mathrm{~K}$, pulse rate of $200 \mathrm{kHz}$, and a detection rate of $0.005-0.01$ ion/pulse in laser mode with laser pulse energy of $50 \mathrm{~nJ}$. The samples for TEM and APT were prepared using the site-specific lift-out technique on a FEI ${ }^{\mathrm{TM}}$ Nova 200 dual beam focused ion beam (FIB). Microhardness measurements were carried out in a Vickers microhardness tester using a load of 500 gf. CALPHAD calculations were performed using TCHEA4 database in ThermoCalc software.

The results from microstructural analysis of high temperature annealed or HRA0 condition are discussed in supplementary information. These results suggest that the colonies of FCC lamellae exhibiting different crystallographic orientations, form within large grains of a parent B2 matrix. The ThermoCalc (using TCHEA4 database) isopleth calculated by varying Al content from 10 to 20 at.\% in $\mathrm{Al}_{\mathrm{x}} \mathrm{CoCrFeNi}$ is shown in Fig. 1(a). An enlarged view of different phase fields 
encountered in $\mathrm{Al}_{\mathrm{x}} \mathrm{CoCrFeNi}$ system during solidification and the high temperature phase fields $\left(>1200^{\circ} \mathrm{C}\right)$ is shown in Fig. 1(b). The composition $\mathrm{Al}_{0.7} \mathrm{CoCrFeNi}$, during solidification, passes through a Liquid (L)+B2 primary solidification phase field and a large $\mathrm{FCC}+\mathrm{B} 2$ phase field below the solidus temperature. Therefore, in case of equilibrium solidification, the expected microstructure is pro-eutectic B2 and a eutectic product resulting from the remaining liquid transforming to $\mathrm{FCC}+\mathrm{B} 2$.

However, under non-equilibrium solidification conditions, when the liquid is fast cooled, partitionless solidification (where the components do not partition between the liquid and the solid product) can take place. The molar Gibbs free energy diagrams in Figures 1(c) and (d) examine the conditions for a partitionless solidification in $\mathrm{Al}_{\mathrm{x}} \mathrm{CoCrFeNi}$. In Fig. 1(c), we have sketched molar Gibbs energy curves of Liquid, B2 and FCC phases below the solidus, and the commontangent construction represents the stable mixture of $\mathrm{B} 2+$ fcc for the $\mathrm{Al}_{0.7} \mathrm{CoCrFeNi}$ alloy which composition lies between the two tangent points. At a given temperature, the limit for the partitionless solidification Liquid $\rightarrow \mathrm{B} 2$ is given by the point of intersection of the two molar Gibbs curves $G_{m}^{L i q u i d}$ and $G_{m}^{B 2}$, at a composition where the phases Liquid and B2 have the same Gibbs energy value. For $\mathrm{Al}$ concentration above this limit, there is a positive driving force for the partitionless solidification Liquid $\rightarrow \mathrm{B} 2$, as illustrated by the vertical arrow for the $\mathrm{Al}_{0.7} \mathrm{CoCrFeNi}$. Molar Gibbs energy differences calculated using the database TCHEA4 (Fig. 1(d)) validate the present analysis and demonstrate that the partitionless solidification of $\mathrm{Al}_{0.7} \mathrm{CoCrFeNi}$ can occur. The as solidified single B2 phase can then decompose into other phases as dictated by thermodynamics and kinetics. In $\mathrm{Al}_{0.7} \mathrm{CoCrFeNi}$, the equilibrium phases below the solidus temperature are FCC, and B2 (refer to Fig. 1 (a)) so the Gibbs free energy of the system can further be lowered, by transforming the polymorphic B2 phase into a mixture of $\mathrm{FCC}$ and $\mathrm{B} 2$ phases. 
Since the nucleation barrier is high for the formation of FCC in BCC, the FCC phase preferentially nucleates at the grain boundaries as allotriomorphs, followed by growth of colonies of FCC lamellae into the B2 grains in a Widmanstatten fashion. Some aspects of this solid-state transformation have been previously discussed in the literature [23] and this microstructure closely resembles the colony-like microstructure observed in case of $\alpha / \beta$ Ti alloys [24].
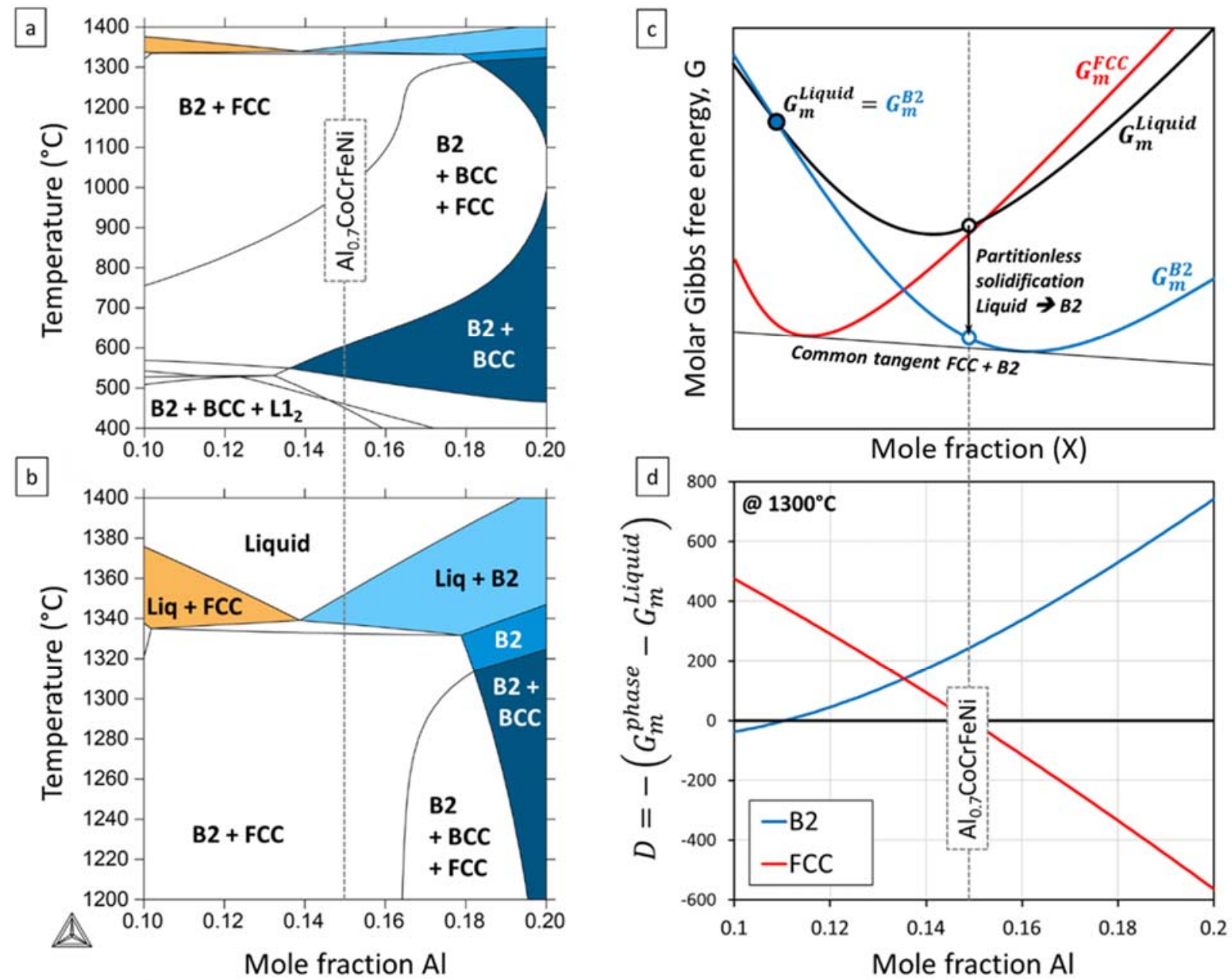

Figure 1: (a-b, d) Thermodynamic modeling using TCHEA4 database in ThermoCalc; (a) Isopleth obtained by varying $\mathrm{Al}$ from 10 to 20 at.\% in $\mathrm{Al}_{\mathrm{x}} \mathrm{CoCrFeNi}$. (b) Enlarged view of the isopleth in (a) in the temperature range of $1200^{\circ} \mathrm{C}-1400^{\circ} \mathrm{C}$. (c) Schematic molar Gibbs energy diagram 
showing the partitionless solidification of liquid to B2 phase. (d) Driving forces for partitionless solidification of $\mathrm{B} 2$ and $\mathrm{FCC}$ calculated at $1300^{\circ} \mathrm{C}$.

The results from microstructural analysis of HRA24 condition $\left(580^{\circ} \mathrm{C} / 24 \mathrm{hrs}\right.$ annealed $)$ are shown in Fig. 2. While the low magnification SEM micrograph in Fig. 2(a) shows the FCC lamellae in B2 matrix, the high magnification micrograph in Fig. 2(b) reveals further decomposition within the B2 matrix. No secondary phases are visible within the FCC lamella at this scale. However, TEM analysis reveals that there are nanoscale $\mathrm{L}_{2}$ precipitates within the FCC lamella as evidenced by the diffraction pattern (inset) and the dark-field image recorded from a $\{001\}$ L12 superlattice reflection in Fig. 2(c). Similarly, a dark field image recorded from a $\{001\}$ B2 superlattice reflection, shown in Fig. 2(d), reveals that there are $\sim 10 \mathrm{~nm}$ spherical BCC precipitates distributed homogenously within the B2 matrix. To understand the microstructural evolution with annealing time, the phase composition of the starting FCC and B2 phases have been determined using SEMEDS. While the composition of FCC lamella was found to be $11.3 \mathrm{Al}-26.33 \mathrm{Cr}-23.57 \mathrm{Fe}-221.39 \mathrm{Co}-$ $17.4 \mathrm{Ni}$ (at\%), the composition of B2 matrix was found to $29.6 \mathrm{Al}-13.4 \mathrm{Cr}-14.2 \mathrm{Fe}-17.1 \mathrm{Co}-25.7 \mathrm{Ni}$ (at\%). Despite a certain amount of interdiffusion at $580^{\circ} \mathrm{C}$, the coarseness of the lamellar microstructure ( microns) results in each of these phases, FCC and B2, behaving as separate subsystems in this hierarchical microstructure. The phase fraction vs temperature plot in supplementary Fig. S4(a) for the FCC lamellae composition, computed using ThermoCalc, shows that the equilibrium phases at $580^{\circ} \mathrm{C}$ are two $\mathrm{B} 2$ phases and one $\mathrm{BCC}$ phase. Therefore, it appears that the experimentally observed FCC and L12 phases, in the HRA24 condition, are in metastable equilibrium. Supplementary table 1 lists the ThermoCalc predicted phase fractions for both the stable condition (two B2 phases and one BCC phase) and the metastable condition via suspending 
the equilibrium B2 and BCC, phases. The absence of the equilibrium B2 phase, can potentially be attributed to the high nucleation barrier associated with its formation within FCC matrix [25]. The composition of these metastable L12 precipitates was determined using APT. Fig. 2(e) shows an Al ion map superimposed with Al 15 at.\% iso-concentration surface. This figure shows the homogenous distribution of $\mathrm{L} 12$ precipitates within the FCC phase. The proxigram [26] or compositional profile across the FCC/ $\mathrm{L}_{2}$ interface is shown in Fig. 2(f). The enrichment of Ni and $\mathrm{Al}$ in the $\mathrm{L}_{2}$ phase and enrichment of $\mathrm{Cr}, \mathrm{Fe}$, and $\mathrm{Co}$ in the $\mathrm{FCC}$ phase can be clearly noted. Interestingly, the decomposition of the $\mathrm{B} 2$ matrix at $580^{\circ} \mathrm{C}$, as predicted by ThermoCalc (shown in Fig. S4(b)) agrees well with the experimentally observed B2 + BCC microstructure (Fig. 2(d)). 


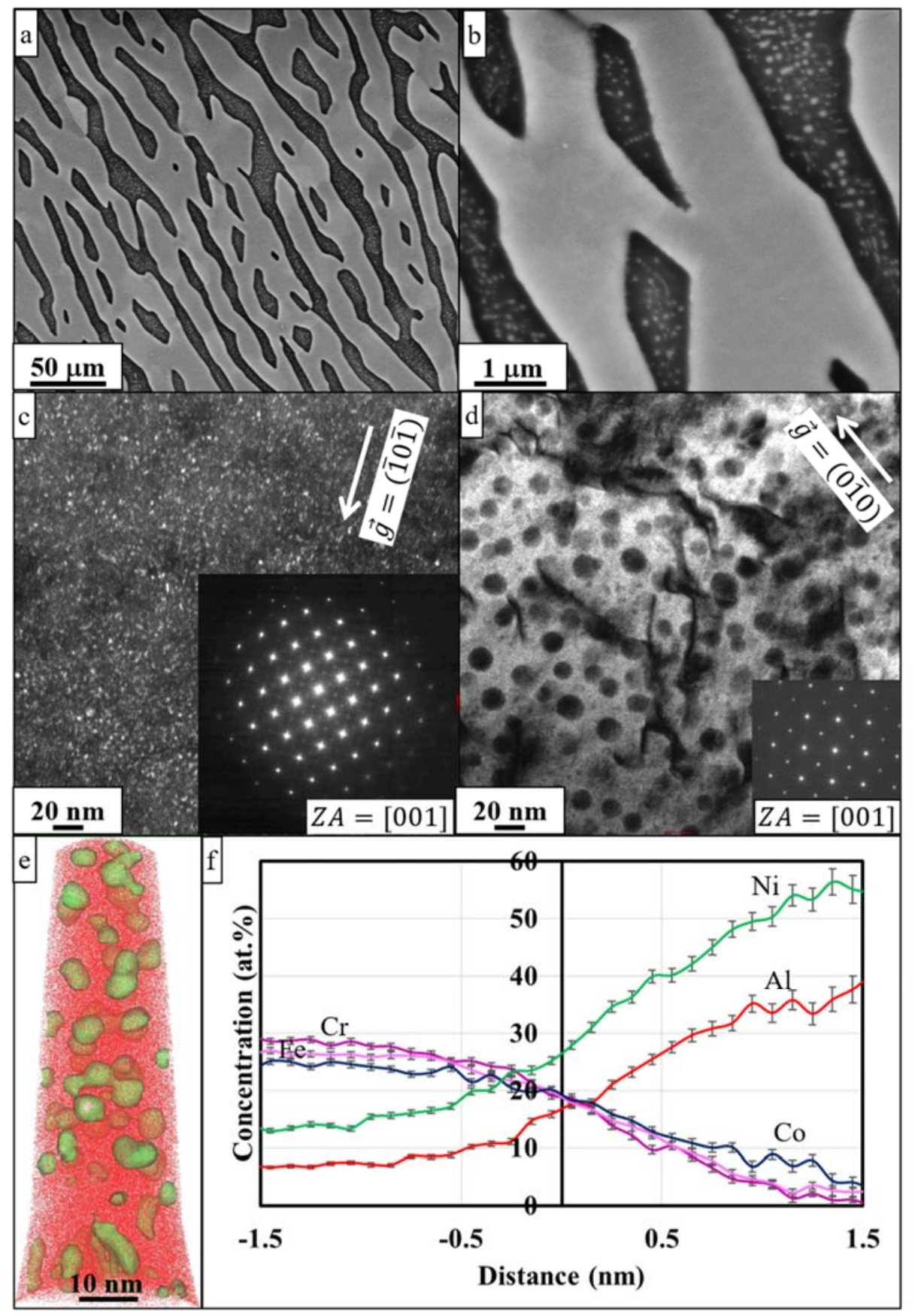

Figure 2: Microstructural characterization of HRA24 condition (a) Low magnification backscattered SEM micrograph showing FCC lamellae in B2 matrix. (b) High magnification SEM micrograph reveals decomposition within FCC lamella and the B2 matrix. (c) Dark field TEM micrograph showing the homogenous distribution of $\mathrm{L}_{2}$ precipitates in FCC lamellae. The 
corresponding diffraction pattern is shown as an inset. (d) Fine-scale distribution of BCC particles within B2 matrix. The corresponding diffraction pattern is shown as an inset. (e) Al ion map superimposed with $\sim 15$ at.\% Al iso-surface showing near spherical L12 particles. (f) Compositional partitioning between FCC and $\mathrm{L}_{2} 2$ phases is shown using a proxigram across $\mathrm{Al} 15$ at. $\%$ iso-surface.

The microstructural analysis of HRA400 condition $\left(580^{\circ} \mathrm{C} / 400 \mathrm{hrs}\right.$ annealed) is summarized in Figs. 3 and 4. A high magnification SEM micrograph (Fig. 3(a)) from this condition reveals lathlike precipitation within the FCC lamellae while the decomposition within the B2 matrix appears similar to the HRA24 condition. A dark field micrograph (Fig. 3(b)) recorded from the $\{002\}$ reflection near $<011>$ zone axis of the FCC phase (inset in Fig. 3(b)), reveals lath-like precipitates. Additionally, it should be noted that the diffraction pattern from the FCC region, shown as an inset in Fig. 3(b), does not exhibit any $\{001\}$ superlattice reflections associated with the $\mathrm{L}_{2}$ phase. These lath-like precipitates do not belong either to the FCC or $\mathrm{L}_{2}$ phases, because these were not highlighted by the dark-field image recorded from the $\{002\}$ reflection. A high magnification bright field image of one such lath-like precipitate is shown in Fig. 3(c). STEM-EDS mapping was carried out to examine the chemical partitioning between the FCC phase and the lath-like precipitates within the lamellae. The Cr K- $\alpha$ map of an FCC lamella is shown in Fig. 3(d). Interestingly, these lath-like precipitates exhibit a composite character consisting of $\mathrm{Cr}$-rich and Cr-lean regions. The Cr-lean regions were found to be rich in Ni and Al. Micro diffraction patterns from the Cr-lean and Cr-rich regions are given in Figs. 3(e, f) respectively. While the diffraction pattern from Cr-lean region can be consistently indexed as B2, the Cr-rich phase was identified to be $\mathrm{BCC}$, as indicated by the presence of $\{001\}$ superlattice reflections in the former and absence 
in the latter case. A high-resolution TEM micrograph recorded from an interface between BCC and B2 phases, shown in Fig. 3(g), further substantiates the presence of adjacent regions of ordered B2 and disordered BCC phases within these lath-like precipitates, embedded within the FCC matrix.

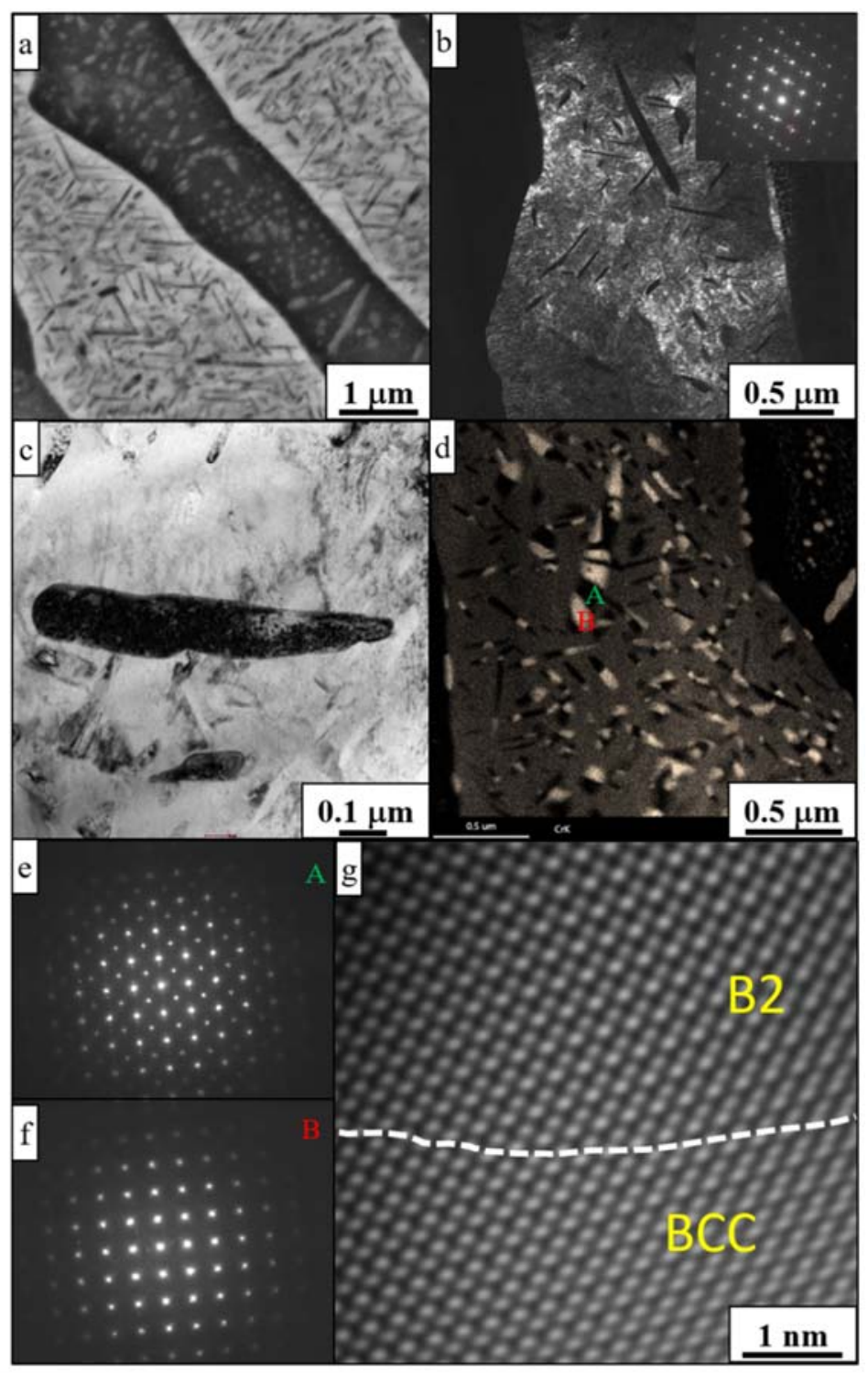

Figure 3: Microstructural characterization of HRA400 condition (a) High magnification backscattered SEM micrograph showing lath like precipitates in FCC lamellae. (b) Dark field TEM micrograph recorded using FCC fundamental reflection. (c) Bright field TEM image of one of the 
lath-like precipitate in FCC lamella. (d) Cr K- $\alpha$ mapping of the FCC lamella showing Cr-rich and Cr-lean regions within lath-like precipitates. (e) Microdiffraction pattern recorded from Cr-lean region, consistently indexed as B2 phase. (f) Microdiffraction pattern recorded from Cr-rich region, consistently indexed as BCC phase. (g) HRTEM micrograph showing the coherent B2BCC interface in one of the lath-like precipitates.

The BCC based composite lath-like precipitates were found to exhibit a K-S orientation relationship with the FCC matrix. This was revealed by the overlap of $\{111\}$ reflections near $<011>$ zone axis from the FCC phase and the $\{011\}$ reflections near $<111>$ zone axis from BCC based composite particles, as shown in Fig. 4(a). A high-resolution TEM micrograph shown in Fig. 4(b), recorded from the interface between FCC and BCC phases, reveals the coherency between these two phases and the K-S orientation relationship. On the other hand, the dark-field image recorded from $\{001\}$ superlattice reflection near the $<001>$ zone axis of the B2 matrix reveals two generations of BCC precipitates (Fig. 4(c)), possibly due to coarsening. The firstgeneration $\mathrm{BCC}$ precipitates were found to have a diameter of $\sim 80 \mathrm{~nm}$ while the second-generation BCC particles have an approximate diameter of $\sim 10 \mathrm{~nm}$. The diffraction pattern used to record this dark field micrograph is given in Fig. 4(d) shows the strong $\{001\}$ reflections arising from large phase fraction of the ordered B2 phase. The compositional partitioning among these different phases in HRA400 condition was further investigated using APT. The superimposed Al, Co, Cr, Fe and Ni raw ion maps are shown in Fig. 4(e). Three compositionally different regions, associated with FCC, BCC and B2 phases, can be observed within the reconstruction volume. The preferential partitioning of all elements between these three different phases is revealed by the $1 \mathrm{D}$ concentration profile constructed across a cylinder shown in Fig. 4(f) which passes through FCC, 
$\mathrm{BCC}$ and $\mathrm{B} 2$ regions. The 1D profile in Fig. 4(g) shows the enrichment of $\mathrm{Co}, \mathrm{Cr}$ and $\mathrm{Fe}$ in $\mathrm{FCC}$, extreme $\mathrm{Cr}$ enrichment in $\mathrm{BCC}$, and $\mathrm{Ni}, \mathrm{A} 1$ enrichment in $\mathrm{B} 2$ phases. The composition of each phase, determined by embedding a sphere of $10 \mathrm{~nm}$ within the phase, is listed in Table 1 .

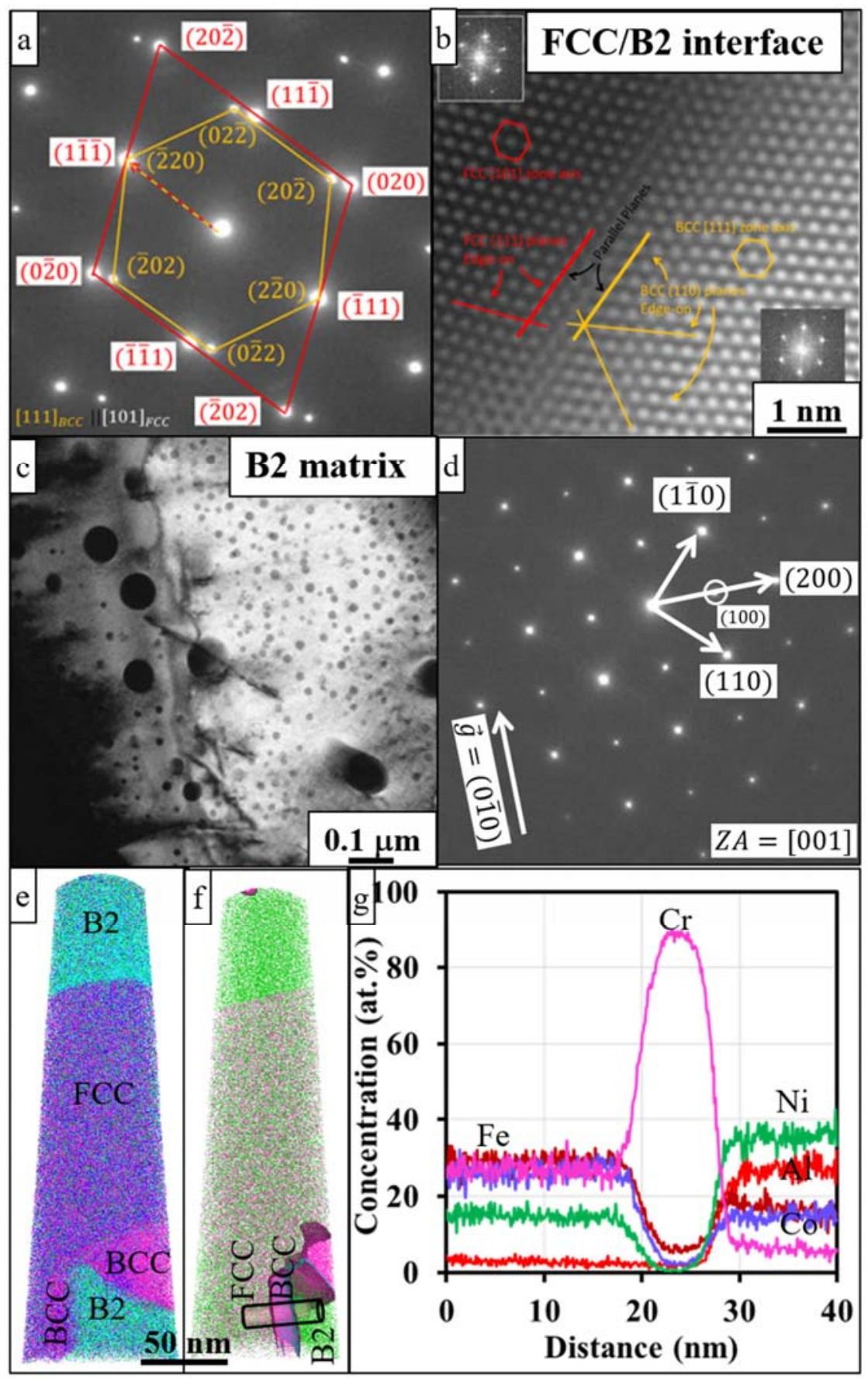


Figure 4: Microstructural characterization of HRA400 condition (a) Diffraction pattern recorded from one of the FCC lamellae revealing K-S OR between B2-BCC composite particles and the FCC phase. (b) HRTEM micrograph of the interface between FCC and BCC phases showing the K-S OR (c) Dark field micrograph obtained using $\{001\}$ superlattice reflection revealing two generations of $\mathrm{BCC}$ precipitates inside the B2 matrix. (d) The diffraction pattern used for dark field imaging in (c). (e) Superimposed ion maps of Al, Co, Cr, Fe, Ni from APT. (f) Superimposed $\mathrm{Ni}$ and $\mathrm{Cr}$ maps along with $\mathrm{Cr} 37.5$ at.\% iso-concentration surface revealing FCC, B2 and BCC phases as indicated on the figure. (g) 1D concentration profile across the cylinder shown in (f) shows the compositional partitioning of all elements among different phases.

Table 1: Composition of different phases in FCC lamellae for HRA24 and HRA400 conditions obtained using APT

\begin{tabular}{|c|c|c|c|c|c|}
\hline Phase & $\begin{array}{c}\text { Al (at.\%) } \pm \\
\text { Sigma \% }\end{array}$ & So (at.\%) \pm & Cr (at.\%) \pm & Fe (at.\%) \pm & Ni (at.\%) \pm \\
Sigma \% & Sigma \% & Sigma \% & Sigma \% \\
\hline FCC & 6.7 & 24.1 & 28.8 & 26.3 & 14.1 \\
\hline \multicolumn{6}{|c|}{ Composition of FCC and L12 phases in HRA24 condition obtained from APT } \\
\hline Composition of FCC, BCC and B2 phases in HRA400 condition obtained from APT \\
\hline FCC \\
\hline \multicolumn{2}{|c|}{45.8} & 4.3 & 0.9 & 2.6 & 56.4 \\
\hline
\end{tabular}




\begin{tabular}{|c|c|c|c|c|c|}
\hline B2 & $30.1 \pm 0.4$ & $15.1 \pm 0.2$ & $5.2 \pm 0.1$ & $12.0 \pm 0.2$ & $37.4 \pm 0.4$ \\
\hline BCC & $1.6 \pm 0.0$ & $2.1 \pm 0.0$ & $90.2 \pm 0.2$ & $5.7 \pm 0.0$ & $0.3 \pm 0.0$ \\
\hline
\end{tabular}

The change in precipitation behavior within the FCC lamellae from metastable $\mathrm{L}_{2}$ to stable composite $\mathrm{B} 2 / \mathrm{BCC}$ precipitates, with increasing in isothermal annealing time at $580^{\circ} \mathrm{C}$, is in agreement with the solution thermodynamic (ThermoCalc) predictions shown in supplementary Fig. S4(a) and the supplementary table S1. Furthermore, it should be noted that even after $400 \mathrm{hrs}$ annealing at $580^{\circ} \mathrm{C}$, the parent $\mathrm{FCC}$ matrix within the lamellae is retained, indicating that the microstructure has not achieved true equilibrium, though being closer to equilibrium as compared to the $580^{\circ} \mathrm{C} / 24 \mathrm{hrs}$ condition. The transformation from the metastable $\mathrm{L} 12$ precipitates to the near equilibrium composite $\mathrm{BCC}+\mathrm{B} 2$ lath-like precipitates within the $\mathrm{FCC}$ lamellae requires further detailed investigation. The heterogeneous nucleation of B2/BCC lath-like precipitates (HRA400) may not be aided by the pre-existing low energy coherent FCC-L12 interfaces (HRA24). However, it is possible that there is a transition phase between the $\mathrm{L}_{2}$ and $\mathrm{B} 2 / \mathrm{BCC}$ phases. While more detailed studies are warranted, the presence of novel L12-like phase, but with a superstructure, has been previously reported in case of the $\mathrm{Al}_{0.3} \mathrm{CoCrFeNi} \mathrm{HEA}$ [25]. Interestingly, the laths formed were found to be a mixture of $\mathrm{Ni}-\mathrm{A} 1$ rich $\mathrm{B} 2$ and $\mathrm{Cr}$-rich BCC. Since the equilibrium phases of FCC lamella composition at the annealing temperature are B2 and BCC (refer to supplementary Fig. S4), formation of these phases in FCC is expected. But the distribution and morphology of these phases in the HRA400 condition can be attributed to interfacial energy. The precipitation of individual $\mathrm{B} 2$ and $\mathrm{BCC}$ precipitates within the FCC matrix results in a large interfacial energy. Instead, the formation of composite $\mathrm{B} 2 / \mathrm{BCC}$ precipitates, with coherent $\mathrm{B} 2 / \mathrm{BCC}$ interfaces, 
substantially reduces the nucleation barrier within the FCC matrix, as compared to individual B2 and BCC precipitates.

Finally, the microstructural changes during isothermal annealing have been associated with microhardness and the results are tabulated in Table 2. Additionally, the microstructural changes occurring in FCC lamellae and B2 matrix have also been listed in Table 2. The HRA condition with FCC lamellae and B2+early stage BCC matrix exhibited the lowest hardness among the three conditions $\sim 270 \mathrm{Hv}$. The precipitation of $\mathrm{L}_{2}{ }_{2}$ inside FCC lamellae in HRA24 condition increased the hardness of the alloy to $\sim 405 \mathrm{Hv}$. The maximum hardness of $\sim 430 \mathrm{Hv}$ was obtained when FCC lamellae were decomposed into FCC and (B2+BCC) composite particles.

Table 2: Microstructural evolution and hardness of different isothermally annealed conditions.

\begin{tabular}{|c|c|c|c|}
\hline \multirow{2}{*}{$\begin{array}{c}\text { Annealing time } \\
\text { (hrs) }\end{array}$} & \multicolumn{2}{|c|}{ Microstructure } & \multirow{2}{*}{ Hardness (Hv0.5) } \\
\cline { 2 - 4 } & FCC lamellae & B2 matrix & \\
\hline 0 & FCC & B2+early-stage BCC & $270.4 \pm 6.5$ \\
\hline 24 & FCC+L12 & B2+BCC & $405.2 \pm 8.8$ \\
\hline 400 & FCC+B2+BCC & B2+BCC & $430.4 \pm 4$ \\
\hline
\end{tabular}


In summary, the phase transformation sequence ensued in $\mathrm{Al}_{0.7} \mathrm{CoCrFeNi}$ during solidification and subsequent annealing has been studied in detail. During solidification, the liquid transforms to a single B2 phase via partitionless solidification followed by the solid-state nucleation and growth of FCC lamellae into B2 grains. Annealing this microstructure at $580^{\circ} \mathrm{C}$ for $24 \mathrm{hrs}$ led to precipitation of $\mathrm{L}_{2} 2$ within FCC lamellae, which dramatically increased the hardness of the alloy. Further increase in annealing time to $400 \mathrm{hrs}$ led to the dissolution of $\mathrm{L}_{2}$ and precipitation of composite $\mathrm{BCC}+\mathrm{B} 2$ laths inside $\mathrm{FCC}$ lamellae. On the other hand, the $\mathrm{B} 2$ matrix remained as a mixture of $\mathrm{B} 2$ and discrete $\mathrm{BCC}$ particles throughout the isothermal annealing process.

\section{Acknowledgements}

The work was supported by the US Air Force Office of Scientific Research under grant FA955017-1-0395. The authors acknowledge the Materials Research Facility (MRF) at the University of North Texas for use of microscopy facilities.

\section{Competing Interests}

None

\section{References}

[1] B. Cantor, Entropy 16 (2014) 4749-4768.

[2] J.W. Yeh, S.K. Chen, S.J. Lin, J.Y. Gan, T.S. Chin, T.T. Shun, C.H. Tsau, S.Y. Chang, Adv. Eng. Mater. 6 (2004) 299-303.

[3] J.Y. He, H. Wang, H.L. Huang, X.D. Xu, M.W. Chen, Y. Wu, X.J. Liu, T.G. Nieh, K. An, Z.P. Lu, Acta Mater. 102 (2016) 187-196. 
[4] T. Yang, Y.L. Zhao, Y. Tong, Z.B. Jiao, J. Wei, J.X. Cai, X.D. Han, D. Chen, A. Hu, J.J. Kai, K. Lu, Y. Liu, C.T. Liu, Science (80-. ). 362 (2018) 933-937.

[5] B. Gwalani, S. Gorsse, D. Choudhuri, Y. Zheng, R.S. Mishra, R. Banerjee, Scr. Mater. (2019).

[6] S. Gorsse, D.B. Miracle, O.N. Senkov, Acta Mater. (2017).

[7] J. Joseph, N. Stanford, P. Hodgson, D.M. Fabijanic, J. Alloys Compd. 726 (2017) 885895.

[8] C. Li, J.C. Li, M. Zhao, Q. Jiang, J. Alloys Compd. 504 (2010).

[9] W.R. Wang, W.L. Wang, J.W. Yeh, J. Alloys Compd. 589 (2014) 143-152.

[10] T. Yang, S. Xia, S. Liu, C. Wang, S. Liu, Y. Zhang, J. Xue, S. Yan, Y. Wang, Mater. Sci. Eng. A 648 (2015) 15-22.

[11] C. Zhang, F. Zhang, H. Diao, M.C. Gao, Z. Tang, J.D. Poplawsky, P.K. Liaw, Mater. Des. 109 (2016) 425-433.

[12] S. Gangireddy, B. Gwalani, R. Banerjee, R.S. Mishra, J. Dyn. Behav. Mater. 5 (2019).

[13] J.C. Rao, H.Y. Diao, V. Ocelík, D. Vainchtein, C. Zhang, C. Kuo, Z. Tang, W. Guo, J.D. Poplawsky, Y. Zhou, P.K. Liaw, J.T.M. De Hosson, Acta Mater. 131 (2017) 206-220.

[14] A.M. Giwa, Z.H. Aitken, P.K. Liaw, Y.W. Zhang, J.R. Greer, Mater. Des. 191 (2020).

[15] B. Gwalani, T. Wang, A. Jagetia, S. Gangireddy, S. Muskeri, S. Mukherjee, J.T. Lloyd, R. Banerjee, R.S. Mishra, Entropy 22 (2020).

[16] X. Gong, C. Xiang, T. Auger, J. Chen, X. Liang, Z. Yu, M.P. Short, M. Song, Y. Yin, Scr. Mater. 194 (2021).

[17] S. Xie, R. Li, T. Yuan, M. Zhang, M. Wang, L. Yin, P. Cao, Mater. Charact. 160 (2020).

[18] A.M. Giwa, P.K. Liaw, K.A. Dahmen, J.R. Greer, Extrem. Mech. Lett. 8 (2016) 220-228. 
[19] G. Liu, L. Liu, X. Liu, Z. Wang, Z. Han, G. Zhang, A. Kostka, Intermetallics 93 (2018) 93-100.

[20] B. Gwalani, S. Gangireddy, Y. Zheng, V. Soni, R.S. Mishra, R. Banerjee, Sci. Rep. 9 (2019).

[21] L.T.H. De Jeer, V. Ocelík, J.T.M. De Hosson, Microsc. Microanal. 23 (2017) 905-915.

[22] U. Hecht, S. Gein, O. Stryzhyboroda, E. Eshed, S. Osovski, Front. Mater. 7 (2020).

[23] Y. Ohmori, K. Nakai, H. Ohtsubo, Y. Isshiki, ISIJ Int. (1995).

[24] D. Banerjee, J.C. Williams, Acta Mater. (2013).

[25] B. Gwalani, S. Gorsse, D. Choudhuri, M. Styles, Y. Zheng, R.S. Mishra, R. Banerjee, Acta Mater. (2018)

[26] O.C. Hellman, J.A. Vandenbroucke, J. Rüsing, D. Isheim, D.N. Seidman, Microsc. Microanal. 6 (2000) 437-444. 